\title{
Assessment of oral bioaccessibility of arsenic in playground soil in Madrid (Spain): A three-method comparison and implications for risk assessment
}

\author{
Juan Mingot, Eduardo De Miguel*, Enrique Chacón \\ Environmental Geochemistry Research and Engineering Laboratory, Universidad Politécnica de Madrid, Alenza 4, E-28003 Madrid, Spain
}

\begin{abstract}
A B S T R A C T
Three methodologies to assess As bioaccessibility were evaluated using playground soil collected from 16 playgrounds in Madrid, Spain: two (Simplified Bioaccessibility Extraction Test: SBET, and hydrochloric acid-extraction: $\mathrm{HCl}$ ) assess gastric-only bioaccessibility and the third (Physiologically Based Extraction Test: PBET) evaluates mouth-gastric-intestinal bioaccessibility. Aqua regia-extractable (pseudo total) As contents, which are routinely employed in risk assessments, were used as the reference to establish the following percentages of bioaccessibility: SBET - 63.1; $\mathrm{HCl}-51.8$; PBET - 41.6, the highest values associated with the gastric-only extractions. For Madrid playground soils - characterised by a very uniform, weakly alkaline $\mathrm{pH}$, and low Fe oxide and organic matter contents - the statistical analysis of the results indicates that, in contrast with other studies, the highest percentage of As in the samples was bound to carbonates and/or present as calcium arsenate. As opposed to the As bound to Fe oxides, this As is readily released in the gastric environment as the carbonate matrix is decomposed and calcium arsenate is dissolved, but some of it is subsequently sequestered in unavailable forms as the $\mathrm{pH}$ is raised to 5.5 to mimic intestinal conditions. The $\mathrm{HCl}$ extraction can be used as a simple and reliable (i.e. low residual standard error) proxy for the more expensive, time consuming, and error-prone PBET methodology. The $\mathrm{HCl}$ method would essentially halve the estimate of carcinogenic risk for children playing in Madrid playground soils, providing a more representative value of associated risk than the pseudo-total concentrations used at present.
\end{abstract}

\section{Introduction}

Children in urban environments are exposed to toxic trace elements in a number of exposure media, i.e. food and drinking water, atmospheric suspended particles, indoor dust at home and at school, street dust, and private garden soil. In large cities with mild climates and an urban architecture dominated by buildings of flats rather than houses, there is an additional exposure pathway of concern: playing activities in outdoor playgrounds during and after school. Several authors have tried to evaluate the relevance of this exposure by means of risk assessments and have concluded that ingestion of soil particles is the exposure pathway that has the highest contribution to the overall figure of risk and that arsenic is clearly the element of most concern (Dudka and Miller, 1999; De Miguel et al., 2007).

A potential problem with that approach arises from the fact that oral toxicity reference values used in risk assessments have been derived from epidemiological studies in which human populations were exposed to As in drinking water (Tseng et al.,
1968; Tseng, 1977; USEPA, 2010), which means that - as opposed to what happens with a solid matrix like playground soil - the bioaccessibility of As (i.e. the fraction of the trace element content that is available in the gastrointestinal tract for transport across the intestinal lumen) was $100 \%$ (the term bioavailability, on the other hand, usually denotes the ingested contaminant fraction that actually reaches the systemic circulation and it takes into account that not all the mass of metal released during its transit in the gastrointestinal tract will be absorbed). Hence, assessments based on total or pseudo-total analytical determinations overestimate risk, since not all that $A s$ is available for absorption in the human body. Although for certain purposes this might be acceptable as a conservative - i.e. protective - scenario, using bioaccessible concentrations of As in soil yields more representative results.

There is a wealth of in vitro studies on the bioaccessibility of trace elements in urban soils (Ljung et al., 2007; Madrid et al., 2008; Rasmussen et al., 2008; Poggio et al., 2009; Roussel et al., 2010). However, there is little agreement on how much of the total content of As in urban soils is bioaccessible, and on which soil properties most influence the percentage of As bioaccesibility. The highly variable and sometimes contradictory 
results arrived at by different researchers reflect the many and complex factors that influence how much of the total trace element load in a sample is bioaccessible (i.e. element investigated, granulometry and mineralogy of the sample, organic carbon content, mode of retention, anthropogenic or natural origin, acid-to-sample ratio in the digestion procedure, etc.). This variability of results is also a consequence of the disparity of extraction protocols employed and the analytical difficulties associated with some of them, especially those which attempt to retrieve both the gastric (trace elements removed from the solid matrix under extraction conditions similar to those existing in the human stomach) and intestinal (previously released elements that remain in solution at conditions resembling those of the human small intestine) fractions of the total contaminant load in the solid sample. These analytical difficulties - which include long extraction times, large number of unstable reactants, concentrations near or below the detection limit - have led a majority of researchers to make use of simplified, gastric-only bioaccessible extraction protocols rather than complete mouth-gastricintestinal methods.

Following the discussion above, the aim of this work is to compare the results of two simplified standard protocols used to evaluate trace element gastric bioaccessibility and one that evaluates mouth-gastric-intestinal bioaccessibility when applied to playground soil, and to discuss the influence of the concentration of major elements and selected soil properties on the bioaaccessibility of As in that material and, hence, in the potential effects on children health in urban environments.

\section{Materials and methods}

The city of Madrid extends over $600 \mathrm{~km}^{2}$ with an estimated population of approximately 3 million inhabitants. The climate in Madrid is continental and relatively mild, with annual average temperature and precipitation of $14.5^{\circ} \mathrm{C}$ and $436 \mathrm{~mm}$, respectively. These weather condition and the traditional Spanish social habits encourage outdoor activities for kids, particularly games in public playgrounds after school, during weekends and holiday periods.

\subsection{Sampling sites, sampling collection and preparation}

Soil samples in this study were collected from the municipal playgrounds specifically designed for children up to 6 years of age which can be found in most parks and municipal green areas of Madrid. In 16 of these playgrounds, two $500 \mathrm{~g}$ samples of surficial substrate were collected with a plastic pan and a brush. This surficial substrate is composed of natural soil covered by a few centimeters of medium-to-coarse sand which is meant to act as an impact-absorption medium to prevent injuries from falls (European Committee for Standardization, 2001). The sand cover eventually mixes with the underlying soil as well as with soil transported from adjacent green areas and wastes, and is normally replaced at 4-12 month intervals. The 32 samples of this material were transferred to polyethylene bags for transport to the laboratory where they were oven dried at $45^{\circ} \mathrm{C}$ for $48 \mathrm{~h}$ and then sieved, in all-plastic sieving sets, through $2 \mathrm{~mm}$, $500 \mu \mathrm{m}$ and $100 \mu \mathrm{m}$ mesh.

The determination of the physicochemical properties was carried out in duplicate on the $<100 \mu \mathrm{m}$ size fraction: soil pH and electrical conductivity were measured in $1: 2$ and $1: 5$ soil:water extracts, respectively, oxidisable organic matter content was determined using the Walkley-Black method, calcium carbonate was determined with the calcimeter Bernard method, and cation exchange capacity was evaluated with ammonium acetate $(1 \mathrm{~N})$.

\subsection{Pseudo-total (i.e. aqua regia extractable) contents}

The fraction $<100 \mu \mathrm{m}$ was reduced by quartering to $0.5 \mathrm{~g}$, which was subsequently digested for $1 \mathrm{~h}$ in a hot water bath $\left(>95^{\circ} \mathrm{C}\right)$ with a 2:2:2 mixture of ACS grade $\mathrm{HCl}$ and $\mathrm{HNO}_{3}$ and de-mineralised water. After cooling, the solution was made up to $10 \mathrm{~mL}$ with $5 \%$ $\mathrm{HCl}$ (adapted from ISO 11466, 1995, according to De Miguel et al., 2007). Trace element and major element concentrations were determined by Inductively Coupled Plasma Optical Emission Spectroscopy (ICP-OES). Quality controls involved two reagents blanks and a certified reference material (STD DS6, Acme Analytical Laboratories) for each batch of 32 samples. (For the sake of brevity aqua regia extractable contents will be referred to as "total" contents in the following sections).

\subsection{Physiologically Based Extraction Test (PBET), following Oomen et al., 2003}

The Physiologically Based Extraction Test (PBET) simulates the mouth, stomach and intestine in terms of digestive juice composition, temperature, $\mathrm{pH}$ and transit time. Transit times in Oomen et al. (2003) were extended to $4 \mathrm{~h}$ in the stomach stage and $3.5 \mathrm{~h}$ in the small intestine stage so as to more accurately reproduce digestion conditions in the human body (DeSesso and Jacobson, $2001)$. Artificial saliva $(9 \mathrm{~mL})$ was added to $0.6 \mathrm{~g}$ of soil $<100 \mu \mathrm{m}$ in centrifuge tubes and the mixture was rotated for $5 \mathrm{~min}$ at $37^{\circ} \mathrm{C}$. Subsequently $13.5 \mathrm{~mL}$ of gastric juice were added and the mixture was rotated for $4 \mathrm{~h}$ at $37^{\circ} \mathrm{C}$. Afterward $36 \mathrm{~mL}$ of intestinal juices ( $27 \mathrm{~mL}$ of duodenal juices and $9 \mathrm{~mL}$ of bile) were added and the mixture was rotated for $3 \mathrm{~h}$ and $30 \mathrm{~min}$ at $37^{\circ} \mathrm{C}$. Finally the mixture was centrifuged for $5 \mathrm{~min}$ at 3000 grav in order to separate the solid (pellets) and the liquid (chyme) fractions. $0.9 \mathrm{~mL}$ of chyme were diluted with $8.1 \mathrm{~mL}$ of $\mathrm{HNO}_{3} 2 \%$ and the resulting solution was analyzed by Inductively Coupled Plasma-Mass Spectrometry (ICP-MS). Details of the composition of each reactant can be found elsewhere (Oomen et al., 2003). Quality controls involved preparation and analysis of five sample triplicates and one blank triplicate. The results were considered acceptable since the relative standard deviation of the replicates was below $10 \%$.

\subsection{Simplified Bioaccessibility Extraction Test (SBET), following Ruby et al., 1999}

In order to determine the glycine-extractable As contents, $0.5 \mathrm{~g}$ of soil $<100 \mu \mathrm{m}$ were mixed with $50 \mathrm{~mL}$ of glycine $(0.4 \mathrm{M})$ at $\mathrm{pH}=1.5$ adjusted with $\mathrm{HCl}$ for $1 \mathrm{~h}$ at $37^{\circ} \mathrm{C}$. The mixture was centrifuged and the supernatant was filtered using Whatman paper number 2. The concentration of As was determined by ICP-MS. Quality controls involved preparation and analysis of five sample triplicates and one blank triplicate. The results were considered acceptable since the relative standard deviation of the replicates was below $10 \%$.

\subsection{Hydrochloric acid-extractable fraction, following Rasmussen et al., 2008}

A modified version of the European Standard Toy Safety Protocol EN-71 (European Committee for Standardization, 1995) proposed by Rasmussen et al. (2008) was used to determine $\mathrm{HCl}$-extractable As contents: $0.05 \mathrm{~g}$ of $<100 \mu \mathrm{m}$ soil were extracted with $50 \mathrm{~mL}$ of $\mathrm{HCl} 0.07 \mathrm{M}\left(\mathrm{pH}=1.5\right.$ adjusted with $\mathrm{HCl}$ ) for $1 \mathrm{~h}$ at $37^{\circ} \mathrm{C}$. The mixture was left standing for an hour and then it was centrifuged, the supernatant was filtered using Whatman paper number 2 . The concentration of As was determined by ICP-MS. Quality controls involved preparation and analysis of five sample triplicates and one 
blank triplicate. The results were considered acceptable since the relative standard deviation of the replicates was below $10 \%$.

The statistical analyses of the analytical data were carried using $\mathrm{R}$ ( $\mathrm{R}$ Development Core Team, 2004). They included descriptive univariate statistics, multiple linear models and a Bayesian Information Criterion (BIC) analysis which, given the large number of variables that could be included in the linear model, some of which are redundant, was used to establish the best - in terms of increased likelihood - and smallest sub-set of predictor variables (Eq. (1)) for the linear models.

$\mathrm{BIC}=-2 \times \log \mathrm{L}+p \times \log n$

where BIC is the Bayesian Information Criterion, L the Likelihood, $p$ the number of parameters, $n$ is the number of data.

\section{Results and discussion}

Table 1 shows the individual results, range, standard deviation, relative standard deviation, mean and median values for the concentration of major elements, $\mathrm{pH}$, electrical conductivity (EC), cation exchange capacity (CEC), and calcium carbonate and organic matter (OM) content of the soils included in this study, as well as the total (i.e. aqua regia extractable), and the gastric-bioaccessible (SBET and $\mathrm{HCl}$ ) and complete gastro-intestinal PBET-bioaccessible concentrations of As following the three extraction methods described in the previous chapter. All the samples of playground soil in Madrid exhibit a very uniform, basic pH of around 8.5. Values of oxidisable organic matter are more variable and generally low, with a median value of $2 \%$ and $78 \%$ of all the results below $3 \%$. Total concentrations of As in playground soil (mean: $6.8 \mu \mathrm{g} \mathrm{g}^{-1}$; range: $4.4-11.5 \mu \mathrm{g} \mathrm{g}^{-1}$ ) are slightly lower and much more uniform than natural background As concentrations in soils across the whole region of Madrid (mean: $9.9 \mu \mathrm{g} \mathrm{g}^{-1}$; range: $0.4-$

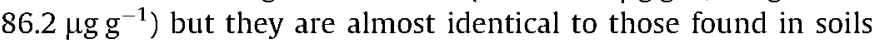
that have developed from the bedrock (i.e. arkose) that underlie the city of Madrid (mean: $6.7 \mu \mathrm{g} \mathrm{g}^{-1}$; range: $1.1-42.9 \mu \mathrm{g} \mathrm{g}^{-1}$ ) (De Miguel et al., 2002).

The percentage of gastric and gastric + intestinal bioaccessibility of As was established through a linear regression of the concentrations of SBET-extractable, $\mathrm{HCl}$-extractable and PBET-extractable As, respectively, on the total concentrations of this element (assuming constant variance of residuals). The linear model was forced to intercept the origin assuming a constant percentage of bioaccessible As in all samples (i.e. the percentage of bioaccessibility is independent of total As content) and zero bioaccessibility at zero total concentration (Fig. 1). The fraction of SBET-bioaccessible arsenic was determined to be $63.1 \%$, the percentage of $\mathrm{HCl}$-bioaccessible As was $51.8 \%$ and PBET-bioaccessible As was $41.6 \%$. The three linear models had $p$-values lower than $2 \times 10^{-16}$ and were therefore highly significant. As expected (Ellickson et al., 2001), gastric-only

Table 1

Soil properties, "pseudo total" (i.e. aqua regia extractable) As and HCl-, SBET-, and PBET-As concentrations in samples from playground surface soil.

\begin{tabular}{|c|c|c|c|c|c|c|c|c|c|c|c|c|c|c|c|c|c|c|}
\hline $\begin{array}{l}\text { Sample } \\
\text { no. }\end{array}$ & $\begin{array}{l}\mathrm{Fe} \\
(\%)\end{array}$ & $\begin{array}{l}\mathrm{Ca} \\
(\%)\end{array}$ & P (\%) & $\begin{array}{l}\mathrm{Mg} \\
(\%)\end{array}$ & $\mathrm{Ti}(\%)$ & $\begin{array}{l}\mathrm{Al} \\
(\%)\end{array}$ & $\begin{array}{l}\mathrm{Na} \\
(\%)\end{array}$ & $\begin{array}{l}\mathrm{K} \\
(\%)\end{array}$ & $\begin{array}{l}\mathrm{Mn} \\
(\%)\end{array}$ & $\begin{array}{l}\mathrm{OM} \\
(\%)\end{array}$ & $\mathrm{pH}$ & $\begin{array}{l}\mathrm{CaCO}_{3} \\
(\%)\end{array}$ & $\begin{array}{l}\text { CEC } \\
\left(\mathrm{cmol} \mathrm{kg}^{-1}\right)\end{array}$ & $\begin{array}{l}\mathrm{EC} \\
\left(\mu \mathrm{S} \mathrm{cm}^{-1}\right)\end{array}$ & $\begin{array}{l}\text { Aqua regia } \\
\text { As }\left(\mu \mathrm{g} \mathrm{g}^{-1}\right)\end{array}$ & $\begin{array}{l}\text { Bioacc. As } \\
\mathrm{HCl}\left(\mu \mathrm{gg}^{-1}\right)\end{array}$ & $\begin{array}{l}\text { Bioacc. As } \\
\text { SBET } \\
\left(\mu g^{-1}\right)\end{array}$ & $\begin{array}{l}\text { Bioacc. As } \\
\text { PBET } \\
\left(\mathrm{mg} \mathrm{kg}^{-1}\right)\end{array}$ \\
\hline $1-1$ & 0.74 & 0.88 & 0.052 & 0.26 & 0.022 & 0.79 & 0.017 & 0.23 & 0.021 & 2.438 & 7.96 & 2.90 & 6.66 & 193 & 7.0 & 4.26 & 5.13 & 3.86 \\
\hline $1-2$ & 0.85 & 0.80 & 0.055 & 0.28 & 0.023 & 0.88 & 0.014 & 0.25 & 0.023 & 2.084 & 8.30 & 2.78 & 5.80 & 154 & 8.2 & 5.18 & 6.58 & 4.65 \\
\hline $2-1$ & 1.21 & 1.70 & 0.211 & 0.39 & 0.028 & 1.14 & 0.019 & 0.40 & 0.033 & 5.329 & 7.92 & 2.56 & 7.26 & 156 & 6.4 & 3.50 & 3.99 & 2.68 \\
\hline $2-2$ & 1.38 & 2.12 & 0.254 & 0.42 & 0.027 & 1.24 & 0.033 & 0.42 & 0.037 & 8.219 & 8.00 & 2.84 & 10.09 & 252 & 7.0 & 4.26 & 4.63 & 2.59 \\
\hline $3-2$ & 1.37 & 0.66 & 0.060 & 0.39 & 0.040 & 1.14 & 0.010 & 0.39 & 0.033 & 1.200 & 8.41 & 2.51 & 5.98 & 124 & 5.7 & 2.76 & 2.32 & 2.28 \\
\hline $3-2$ & 1.35 & 0.64 & 0.061 & 0.39 & 0.042 & 1.15 & 0.011 & 0.38 & 0.032 & 1.249 & 8.55 & 2.14 & 4.66 & 115 & 6.1 & 2.68 & 2.70 & 2.19 \\
\hline 4-1 & 1.04 & 2.40 & 0.067 & 0.63 & 0.026 & 0.96 & 0.032 & 0.27 & 0.028 & 1.478 & 8.29 & 4.83 & 19.46 & 364 & 5.5 & 3.82 & 3.77 & 3.03 \\
\hline 4-2 & 0.97 & 1.38 & 0.064 & 0.37 & 0.022 & 0.67 & 0.009 & 0.19 & 0.025 & 2.102 & 8.82 & 1.98 & 7.27 & 105 & 6.1 & 3.28 & 3.93 & 2.81 \\
\hline 5-1 & 0.98 & 8.32 & 0.059 & 0.30 & 0.018 & 0.83 & 0.010 & 0.24 & 0.027 & 2.384 & 8.68 & 7.21 & 19.89 & 160 & 11.5 & 5.28 & 8.34 & 3.95 \\
\hline $5-2$ & 0.80 & 8.53 & 0.038 & 0.25 & 0.014 & 0.68 & 0.009 & 0.18 & 0.024 & 1.484 & 8.96 & 6.77 & 19.55 & 141 & 8.4 & 4.72 & 7.31 & 2.94 \\
\hline $6-1$ & 1.14 & 3.67 & 0.053 & 0.32 & 0.019 & 0.64 & 0.009 & 0.16 & 0.028 & 1.852 & 8.92 & 3.70 & 19.69 & 139 & 9.0 & 4.06 & 5.50 & 3.55 \\
\hline $6-2$ & 1.23 & 3.15 & 0.058 & 0.34 & 0.022 & 0.64 & 0.008 & 0.18 & 0.028 & 2.753 & 8.66 & 3.90 & 18.75 & 138 & 10.0 & 3.72 & 5.14 & 3.55 \\
\hline $7-1$ & 1.18 & 2.61 & 0.055 & 0.39 & 0.026 & 0.76 & 0.007 & 0.22 & 0.031 & 2.896 & 8.83 & 2.70 & 17.08 & 174 & 7.4 & 3.76 & 4.39 & 3.29 \\
\hline $7-2$ & 1.00 & 3.14 & 0.045 & 0.34 & 0.020 & 0.61 & 0.007 & 0.16 & 0.030 & 2.197 & 8.90 & 3.36 & 18.48 & 131 & 7.1 & 3.74 & 4.50 & 3.03 \\
\hline 8-1 & 0.90 & 3.16 & 0.058 & 0.39 & 0.023 & 0.77 & 0.008 & 0.20 & 0.026 & 2.020 & 8.76 & 3.06 & 18.27 & 124 & 7.4 & 4.70 & 5.37 & 3.69 \\
\hline $8-2$ & 0.85 & 2.59 & 0.060 & 0.34 & 0.019 & 0.68 & 0.008 & 0.19 & 0.025 & 4.437 & 8.38 & 2.64 & 16.87 & 149 & 5.9 & 4.42 & 3.98 & 2.54 \\
\hline 9-1 & 1.21 & 0.61 & 0.051 & 0.32 & 0.028 & 0.84 & 0.014 & 0.24 & 0.040 & 1.532 & 8.78 & 1.68 & 6.30 & 102 & 6.5 & 3.32 & 2.91 & 2.63 \\
\hline $9-2$ & 1.19 & 0.68 & 0.057 & 0.33 & 0.027 & 0.92 & 0.012 & 0.24 & 0.039 & 0.765 & 9.00 & 1.66 & 5.42 & 25 & 6.1 & 3.14 & 3.21 & 2.76 \\
\hline $10-1$ & 0.71 & 1.32 & 0.052 & 0.22 & 0.016 & 0.64 & 0.006 & 0.17 & 0.019 & 1.493 & 8.83 & 1.83 & 10.52 & 86 & 6.3 & 2.84 & 3.07 & 2.50 \\
\hline $10-2$ & 0.73 & 1.08 & 0.057 & 0.21 & 0.016 & 0.76 & 0.015 & 0.20 & 0.017 & 2.690 & 8.62 & 1.71 & 7.79 & 153 & 4.4 & 2.90 & 3.20 & 2.02 \\
\hline $11-1$ & 0.97 & 2.58 & 0.067 & 0.27 & 0.022 & 0.70 & 0.010 & 0.21 & 0.023 & 3.514 & 8.89 & 3.87 & 18.08 & 129 & 5.9 & 3.42 & 4.12 & 2.59 \\
\hline $11-2$ & 0.66 & 1.16 & 0.049 & 0.18 & 0.012 & 0.67 & 0.019 & 0.17 & 0.015 & 3.316 & 8.40 & 2.31 & 12.71 & 180 & 4.7 & 3.30 & 3.51 & 2.76 \\
\hline $12-1$ & 1.01 & 0.63 & 0.045 & 0.25 & 0.022 & 0.69 & 0.011 & 0.21 & 0.024 & 1.941 & 8.33 & NA & NA & 115 & 8.2 & 3.34 & 3.70 & 2.98 \\
\hline $12-2$ & 0.84 & 0.47 & 0.038 & 0.21 & 0.016 & 0.58 & 0.006 & 0.14 & 0.018 & $\mathrm{NA}$ & 8.45 & NA & NA & 87 & 4.8 & 2.38 & 3.56 & 2.15 \\
\hline $13-1$ & 0.92 & 1.14 & 0.053 & 0.30 & 0.022 & 0.82 & 0.007 & 0.19 & 0.021 & 0.466 & 7.99 & NA & NA & 284 & 5.4 & 2.94 & 2.84 & 2.02 \\
\hline $13-2$ & 1.00 & 0.96 & 0.053 & 0.30 & 0.023 & 0.80 & 0.007 & 0.19 & 0.021 & 0.659 & 8.46 & NA & 7.77 & 110 & 5.4 & 2.62 & 2.79 & 2.37 \\
\hline $14-1$ & 0.80 & 2.65 & 0.050 & 0.21 & 0.019 & 0.61 & 0.008 & 0.17 & 0.021 & 1.989 & 8.56 & 4.16 & 19.94 & 154 & 5.9 & 2.94 & 4.00 & 2.24 \\
\hline $14-2$ & 0.70 & 0.65 & 0.038 & 0.16 & 0.015 & 0.45 & 0.006 & 0.14 & 0.020 & 1.039 & 8.66 & 1.73 & 7.82 & 104 & 6.4 & 2.52 & 2.53 & 2.11 \\
\hline $15-1$ & 1.28 & 1.25 & 0.054 & 0.37 & 0.021 & 1.25 & 0.009 & 0.30 & 0.048 & 0.642 & 8.59 & 2.04 & 9.98 & 94 & 6.4 & 3.14 & 3.63 & 2.90 \\
\hline $15-2$ & 1.28 & 1.19 & 0.073 & 0.38 & 0.018 & 1.31 & 0.015 & 0.31 & 0.033 & 0.849 & 8.62 & 1.93 & 10.99 & 94 & 6.2 & 2.80 & 3.13 & 2.41 \\
\hline $16-1$ & 1.22 & 2.42 & 0.088 & 0.34 & 0.023 & 0.99 & 0.023 & 0.28 & 0.039 & 3.193 & 8.34 & 2.12 & 10.79 & 185 & 7.7 & 4.22 & 6.22 & 3.03 \\
\hline $16-2$ & 1.43 & 2.53 & 0.099 & 0.38 & 0.029 & 1.14 & 0.025 & 0.32 & 0.043 & 3.844 & 8.38 & 1.73 & 10.62 & 142 & 8.5 & 4.56 & 6.04 & 3.64 \\
\hline Mean & 1.03 & 2.10 & 0.068 & 0.32 & 0.023 & 0.84 & 0.013 & 0.24 & 0.028 & 2.324 & 8.54 & 2.95 & 12.22 & 146 & 6.8 & 3.58 & 4.25 & 2.87 \\
\hline Median & 1.00 & 1.35 & 0.056 & 0.33 & 0.022 & 0.78 & 0.010 & 0.21 & 0.027 & 2.020 & 8.58 & 2.60 & 10.62 & 139 & 6.4 & 3.38 & 3.95 & 2.76 \\
\hline Std. dev. & 0.23 & 1.91 & 0.045 & 0.09 & 0.006 & 0.23 & 0.007 & 0.08 & 0.008 & 1.587 & 0.30 & 1.42 & 5.52 & 63 & 1.5 & 0.79 & 1.45 & 0.64 \\
\hline $\begin{array}{c}\text { Rel. std. } \\
\text { dev. } \\
(\%)\end{array}$ & 22 & 91 & 67 & 28 & 29 & 27 & 57 & 33 & 29 & 68 & 4 & 48 & 45 & 43 & 23 & 22 & 34 & 22 \\
\hline Max. & 1.43 & 8.53 & 0.254 & 0.63 & 0.042 & 1.31 & 0.033 & 0.42 & 0.048 & 8.219 & 9.00 & 7.21 & 19.94 & 364 & 11.5 & 5.28 & 8.34 & 4.65 \\
\hline Min. & 0.66 & 0.47 & 0.038 & 0.16 & 0.012 & 0.45 & 0.006 & 0.14 & 0.015 & 0.466 & 7.92 & 1.66 & 4.66 & 25 & 4.4 & 2.38 & 2.32 & 2.02 \\
\hline
\end{tabular}




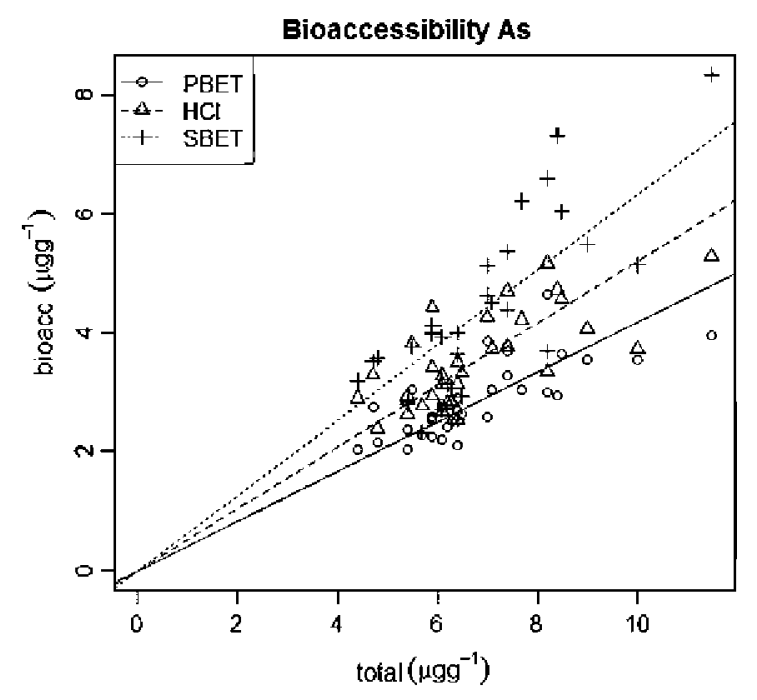

Fig. 1. Linear regression of the concentrations $\left(\mu \mathrm{g} \mathrm{g}^{-1}\right.$ ) of SBET-extractable, $\mathrm{HCl}$ extractable and PBET-extractable As, respectively, on the aqua regia concentrations $\left(\mu \mathrm{g} \mathrm{g}^{-1}\right)$ of arsenic.

bioaccessibility was higher in both cases (SBET and $\mathrm{HCl}$ ) than PBETbioaccessibility, which replicates both the gastric and intestinal phases.

The results of the SBET extraction differ from the gastric + intestinal (i.e. PBET-) bioaccessible values more than those of the $\mathrm{HCl}$ extraction, a fact that is reflected in the correlation coefficients between the three methods. Although all of them are significantly correlated, with the highest correlation coefficient $(r=0.893)$ occurring between both simplified protocols (SBET and $\mathrm{HCl}$ ), the results of the PBET are more strongly correlated to those of the $\mathrm{HCl}$ protocol $(r=0.825)$ than to those resulting from the SBET $(r=0.776)$. This fact is in accordance with the results reported by Cui et al. (2008) who also found that SBET produced higher extraction rates of As than the gastric stage of gastro-intestinal (i.e. PBET, IVG) protocols. This increased capacity to mobilize As from the solid matrix and to keep it in solution is probably a consequence of the pH-buffering and metal-complexing properties of glycine, which result in higher As concentrations dissolved in the supernatant of the SBET than in the $\mathrm{HCl}$-only extraction protocol.

If compared with similar studies elsewhere (Table 2), the gastrointestinal bioaccessibility of As in playground soils in Madrid is almost identical to that found by Hamel et al. (1999) in the $<125 \mu \mathrm{m}$ fraction of the residential soils in New Jersey, and very similar to that reported by Carrizales et al. (2006), even though these studies analysed soil samples with significantly higher concentrations of total As than those found in Madrid. On the other hand, Ljung et al. (2007), using the same PBET extraction protocol on playground soils in Uppsala, arrived at gastro-intestinal bioaccessibility rates nearly three times lower than those determined in this study. The discrepancy can be attributed to the higher Fe and organic matter contents in Uppsala's playground soils $(2.49 \%$ and $6.8 \%$, respectively, versus $1.03 \%$ and $2.3 \%$ in Madrid) and to the lower $\mathrm{pH}$ (between 4.7 and 8.1 in Uppsala, as opposed to 7.9-9.0 in Madrid), facts which combined account for a higher density of binding sites for As and a reduced desorption potential relative to Madrid's soils.

Regarding the gastric-only bioaccessibility of As, Juhasz et al. (2007), following the same SBET protocol, found bioaccessibility rates for As-contaminated soils along a railway corridor in Australia which were nearly half of those determined for Madrid playgrounds. Again, the lower bioaccessibility might be associated with the higher Fe contents in the Australian soils. Intermediate bioaccessibility values between those of Juhasz et al. (2007) and the results of this study were reported by Yang et al. (2002) in 36 As-spiked soil samples with very similar Fe and organic matter contents to those of Madrid's playgrounds but with markedly lower $\mathrm{pH}$ values which inhibit desorption in the gastric solution. Lastly, Ellickson et al. (2001) arrived at results quite similar to those of this study, after extracting four samples of a NIST Standard using a gastric synthetic fluid which included $0.03 \mathrm{M}$ sodium chloride, $0.084 \mathrm{M}$ hydrochloric acid, and $0.32 \%(\mathrm{w} / \mathrm{v})$ pepsin.

The assessment of which variables most strongly influence the percentage of bioaccessible As in the samples was carried out by means of a multiple linear model and a Bayesian Information Criterion (BIC) analysis. The optimal subset of predictor variables consisted of nine variables for the $\mathrm{HCl}$ extraction and eight for both the SBET and PBET. Total As, Fe, Ca, Ti, Al, K and organic matter (OM) were included in all three multiple linear models. As opposed to what has been found by other authors (Yang et al., 2002; Juhasz et al., 2007), soil pH was not significantly correlated with any of the bioaccessibility methods, but this is very likely a consequence of the very low variability of $\mathrm{pH}$ in the set of samples. Calcium carbonate and cation exchange capacity were also excluded from the optimal subset of predictor variables. The linear models for the three extraction methods are shown in Table 3.

It is worth noting that despite the analytical difficulties involved in the PBET, its results exhibit a lower variability due to measurements errors - measured as residual standard error - than the SBET (although slightly higher than the $\mathrm{HCl}$ extraction). The PBET also presents a lower sensitivity in response to changes on soil nature and mode of retention of As onto the solid matrix - represented by the variables included in the linear models - than both simplified extraction protocols.

The two most significant variables in the linear models for all three extraction methods are total As and $\mathrm{Fe}$, the latter with a

Table 2

Comparison of different studies of As bioaccessibility in soil.

\begin{tabular}{|c|c|c|c|c|c|c|}
\hline Study & Mean (\%) & Range (\%) (std. dev.) & Extraction method & Soil use/type & Particle size $(\mu \mathrm{m})$ & No. samples \\
\hline \multicolumn{7}{|l|}{ Gastric + intestinal } \\
\hline Ljung et al. (2007) & 16.1 & - & Oomen et al. (2003) & Playground & $<50$ & 25 \\
\hline Ellickson et al., 2001 & 65.0 & $(5.2)$ & Hamel et al. $(1999,1998)$ & NIST standard & $<74$ & 4 \\
\hline Carrizales et al. (2006) & 46.5 & $39-66$ & Ruby et al. $(1993,1996)$ & Contaminated & $<50$ & 10 \\
\hline Hamel et al. (1999) & 66.8 & (8) & Hamel et al. $(1999,1998)$ & Standard & $<74$ & 4 \\
\hline Hamel et al. (1999) & 41.2 & (2) & Hamel et al. $(1999,1998)$ & Residential & $<125$ & 4 \\
\hline Mingot et al. - PBET & 41.6 & $32.9-58.8$ & Oomen et al. (2003) & Playground & $<100$ & 32 \\
\hline \multicolumn{7}{|l|}{ Gastric } \\
\hline Yang et al. (2002) & 43.6 & $5.4-100$ & Ruby et al. (1996) & As-spiked & $<250$ & 36 \\
\hline Juhasz et al. (2007) & 34.0 & $6-89$ & Ruby et al. (1996) & Contaminated & $<250$ & 18 \\
\hline Ellickson et al. (2001) & 69.4 & $(8.3)$ & Hamel et al. $(1999,1998)$ & NIST standard & $<74$ & 4 \\
\hline Mingot et al. - SBET & 63.1 & $40.6-80.7$ & Juhasz et al. (2007) & Playground & $<100$ & 32 \\
\hline Mingot et al. $-\mathrm{HCl}$ & 51.8 & $37.2-74.9$ & Rasmussen et al. (2008) & Playground & $<100$ & 32 \\
\hline
\end{tabular}


Table 3

Linear models with the results of the three extraction methods as dependent variables and the BIC optimal subset of soil properties as independent variables.

\begin{tabular}{|c|c|c|}
\hline Linear model & $\begin{array}{l}\text { Adjusted } \\
R \text {-squared }\end{array}$ & p-Value \\
\hline$[$ PBET-As $]=-0.461+0.503[$ Total-As $]-2.801[\mathrm{Fe}]-0.121[\mathrm{Ca}]+2.299[\mathrm{Mg}]+60.915[\mathrm{Ti}]+3.850[\mathrm{Al}]-11.252[\mathrm{~K}]+0.160[\mathrm{OM}]$ & 0.740 & $2.5 \times 10^{-6}$ \\
\hline$[\mathrm{HCl}-\mathrm{As}]=0.116+0.398[\mathrm{Total}-\mathrm{As}]-4.647[\mathrm{Fe}]+0.078[\mathrm{Ca}]+2.007[\mathrm{Mg}]+98.388[\mathrm{Ti}]+4.828[\mathrm{Al}]-14.250[\mathrm{~K}]+0.346[\mathrm{OM}]+37.293[\mathrm{Mn}]$ & 0.872 & $4.6 \times 10^{-9}$ \\
\hline$[$ SBET-As $]=-1.657+0.710[$ Total-As $]-4.068[\mathrm{Fe}]+0.291[\mathrm{Ca}]+35.706[\mathrm{Na}]+102.156[\mathrm{Ti}]+6.615[\mathrm{Al}]-18.530[\mathrm{~K}]+0.303[\mathrm{OM}]$ & 0.877 & $8.8 \times 10^{-10}$ \\
\hline
\end{tabular}

negative partial correlation with bioaccessible As. While total As and Fe exhibit a relatively weak but positive total correlation $(r=0.238, p=0.189)$, and bioaccessible As and Fe are essentially uncorrelated (PBET-As/Fe: $r=0.053, \quad p=0.771 ; \quad$ SBET-As/Fe: $r=-0.021, p=0.909 ; \mathrm{HCl}-\mathrm{As} / \mathrm{Fe}: r=0.022, p=0.903)$, the multiple linear model shows a negative partial correlation between bioaccessible As and total Fe. These facts together seem to indicate that only a fraction of the total Fe in the sample is associated with Fe oxides/hydroxides which effectively bind As (higher Fe concentrations result in higher total As contents) and that this As is not readily released in the acidic environments created in all three extraction processes (higher Fe concentrations result in lower bioaccessibility rates, once the effect of the increase in total As is removed).

Regarding the potential binding of As to natural organic matter, total As and PBET-bioaccessible As are uncorrelated with organic matter ( $r=0.1131, p=0.544$ and $r=0.1129, p=0.545$, respectively) while SBET- and $\mathrm{HCl}$-bioaccessible As exhibit a weak and positive correlation. The multiple linear models show that bioaccessible As is significantly related with organic matter in the results of all three extraction methods, particularly in the $\mathrm{HCl}$ protocol, but as opposed to what happens with Fe, the partial correlations are positive. These facts seem to indicate that relative to other retention mechanisms, organic matter does not contribute significantly to the overall As content in Madrid's samples, but the small fraction of the total As bound to humic substances is released in the gastric and gastro-intestinal environments simulated in the three extraction methods. Since lowering the $\mathrm{pH}$ should not promote the desorption of As directly bound to polar groups in organic matter, the release of OM-bound As hints at a different mechanism of retention. A likely possibility involves binding of As to OM through a polyvalent-cation (very likely, $\mathrm{Ca}$ ) bridging mechanism in which As anions and negatively charged groups in soil OM are joined through positively charged cations (Klitzke and Lang, 2009). In the highly acidic solutions created in all three extraction processes, especially in the $\mathrm{HCl}$-only method, these $\mathrm{Ca}$-bridges would break up and As would be released.

It is interesting to note that total As is strongly correlated with $\mathrm{Ca}$ (but not with $\mathrm{Fe}$ and $\mathrm{OM}$ ). The association of As with Ca can be attributed, in part, to the mechanism described in the previous paragraph, but is in all likelihood mostly due to As adsorption on carbonate surfaces through ligand exchange or chemisorption (Sadiq, 1997) or to the presence of Ca-As precipitates in the alkaline soils included in this study (Sadiq, 1997; Klitzke and Lang, 2009). The mineral matrix of 8 selected samples was investigated by X-ray Diffraction (XRD), including preparation of oriented aggregates, in order to confirm the hypothesised binding mechanisms. The results, however, are inconclusive: although in two of those samples there seem to be two peaks that could be associated with $\mathrm{Ca}$ arsenite and arsenate, respectively, their intensity is too low to use it as proof of their presence in our samples.

The linear model shows that bioaccessible As is positively correlated with $\mathrm{Ca}$ in both the $\mathrm{HCl}$ and especially the SBET protocols, but negatively correlated in the PBET extracts. These facts suggest that As is released in the gastric environment as the carbonate matrix is decomposed and as calcium arsenate is dissolved. When the $\mathrm{pH}$ is raised in the PBET extract to 5.5 to mimic intestinal conditions, arsenic seems to get sequestered in unavailable chemical forms at a higher rate than $\mathrm{Ca}$, hence the negative correlation of PBET-As and $\mathrm{Ca}$ in the linear model.

Although the concentrations of $\mathrm{Al}, \mathrm{Ti}$, and $\mathrm{K}$ are also significant in the linear model, the authors are unaware of the physico-chemical mechanisms that could explain the lack of correlation of these variables with total As and their positive, in the case of $\mathrm{Al}$ and $\mathrm{Ti}$, and negative, in the case of $\mathrm{K}$, partial correlation with bioaccessible As.

\section{Conclusions}

The results of this study highlight the strong dependence of As bioaccessibility on soil type and soil properties. The highly homogeneous, weakly alkaline nature of the soils in Madrid's playgrounds differs quite markedly from that of soils included in similar studies elsewhere, and the magnitude of As bioaccessibility and the underlying physico-chemical mechanisms of release/ retention vary accordingly. As opposed to what has been found for other soils, total As in the samples from public playgrounds in Madrid seems to be mainly bound to carbonate materials (although the direct mineralogical analyses carried out have failed to provide unequivocal evidence for this retention mechanism) but uncorrelated with organic matter and $\mathrm{pH}$, and only slightly correlated with Fe. In weakly alkaline soils, with low contents of Fe oxides and organic matter - as is the case in this study - the As released in the simulated gastric environment reaches between $63 \%$ (SBET-bioaccessible) and 52\% (HCl-bioaccessible) of the total, and a fraction of it is recaptured and removed from the solution under intestinal conditions, bringing the percentage of As available for effective absorption (PBET-bioaccessible) down to $42 \%$ of the total.

Although a complete in vitro extraction test like the PBET which reproduces both the gastric and the intestinal environments - reflect the actual in vivo bioavailability of trace elements in soil more accurately than gastric-only extraction methods, it is an expensive and time-consuming analytical protocol. For the soils included in this study, if the PBET were to be replaced by a more simple, gastric-only method, the estimates of As bioaccessibility of the $\mathrm{HCl}$-only extraction present the lowest measurement errors and approximate the results of the PBET better than methods like the SBET which incorporate glycine in the gastric phase and which yield higher extraction rates.

If $\mathrm{HCl}$-As values are used as a conservative (i.e. protective) proxy for bioavailable As in Madrid's OM and Fe-oxide poor, alkaline soils, previous estimates of carcinogenic risk for children from exposure to playground soil (close to the $1 \times 10^{-5}$ level deemed unacceptable by most regulatory agencies) based on aqua regia concentrations would be halved. Although a $50 \%$ reduction is not trivial, it is debatable whether the outcome of the risk model would not be more sensitive to other sources of uncertainty like estimates of toxicity values (with an acknowledged uncertainty spanning one order of magnitude), exposure parameters and levels of non-environmental background exposure.

\section{Acknowledgments}

The authors would like to express their enormous gratitude to Dr. Isabel de Soto for her analytical work and helpful comments. 
We are also very much indebted to the anonymous referees whose comments have greatly improved the quality of this manuscript.

\section{References}

Carrizales, L., Razo, I., Téllez-Hernández, J., Torres-Nerio, T., Torres, A., Batres, L., Cubillas, A.C., Díaz-Barriga, F., 2006. Exposure to arsenic and lead of children living near a copper-smelter in San Luis Potosi, Mexico: importance of soil contamination for exposure of children. Environ. Res. 101, 1-10.

Cui, Y.-S., Chen, X.-C., Zhu, Y.-G., 2008. Comparison of three in vitro methods to study the bioaccessibility of soil lead and arsenic. J. Agro-Environ. Sci. 27, 414419.

De Miguel, E., Callaba, A., Arranz, J., Cala, V., Chacón, E., Gallego, E., Alberruche, E., Alonso, C., Fernández-Canteli, P., Iribarren, I., Palacios, H., 2002. Determinación de niveles de fondo $y$ niveles de referencia de metales pesados y otros elementos traza en suelos de la Comunidad de Madrid. Instituto Geológico y Minero de España, Madrid in Spanish.

De Miguel, E., Iribarren, I., Chacôn, E., Ordoñez, A., Charlesworth, S., 2007. Riskbased evaluation of the exposure of children to trace elements in playgrounds in Madrid Spain. Chemosphere 66, 505-513.

DeSesso, J.M., Jacobson, C.F., 2001. Anatomical and physiological parameters affecting gastrointestinal absorption in humans and rats. Food Chem. Toxicol. $39,209-228$.

Dudka, S., Miller, W.P., 1999. Permissible concentrations of arsenic and lead in soils based on risk assessment. Water Air Soil Pollut. 113, 127-132

Ellickson, K.M., Meeker, R.J., Gallo, M.A., Buckley, B.T., Lioy, P.J., 2001. Oral bioavailability of lead and arsenic from a NIST standard reference soil material. Arch. Environ. Contam. Toxicol. 40, 128-135.

European Committee for Standardization, 1995. EN-71: Safety of Toys - Part 3: Specification for Migration of Certain Elements. British Standard EN 71-3.

European Committee for Standardization, 2001. Impact Absorbing Playground Surfacing. Safety Requirements and Test Methods. EN 1177:1997/A1.

Hamel, S.C., Buckley, B., Lioy, P.J., 1998. Bioaccessibility of metals in soils for different liquid to solid ratios in synthetic gastric fluid. Environ. Sci. Technol. 323, 358-362.

Hamel, S.C., Ellickson, K.M., Lioy, P.J., 1999. The estimation of the bioaccessibility of heavy metals in soils using artificial biofluids by two novel methods: massbalance and soil recapture. Sci. Total Environ. 243-244, 273-283.

Juhasz, A.L., Smith, E., Weber, J., Rees, M., Rofe, A., Kuchel, T., Sansom, L., Naidu, R., 2007. In vitro assessment of arsenic bioaccessibility in contaminated anthropogenic and geogenic soils. Chemosphere 69, 69-78.

Klitzke, S., Lang, F., 2009. Mobilization of soluble and dispersible lead, arsenic and antimony in a polluted, organic-rich soil - effects of $\mathrm{pH}$ increase and counterion valency. J. Environ. Qual. 38, 933-939.
Ljung, K., Oomen, A., Duits, M., Selinus, O., Berglund, M., 2007. Bioaccessibility of metals in urban playground soils. J. Environ. Sci. Health 42, 1241-1250.

Madrid, F., Biasioli, M., Ajmone-Marsan, F., 2008. Availability and bioaccessibility of metals in fine particles of some urban soils. Arch. Environ. Contam. Toxicol. 55, $21-32$

Oomen, A.G., Rompelberg, C.J.M., Bruil, M.A., Dobbe, C.J.G., Pereboom, D.P.K.H., Sips, A.J.A.M., 2003. Development of an in vitro digestion model for estimation of bioaccessibility of soil contaminants. Arch. Environ. Contam. Toxicol. 44, 281287

Poggio, L., Vrscaj, B., Schulin, R., Hepperle, E., Ajmone Marsan, F., 2009. Metals pollution and human bioaccessibility of topsoils in Grugliasco Italy. Environ. Pollut. 157, 680-689.

R Development Core Team, 2004. R: A Language and Environment for Statistical computing, $R$ Foundation for Statistical Computing. <http://www.Rproject.org>.

Rasmussen, P.E., Beauchemin, S., Nugent, M., Dugandzic, R., Lanouette, M., Chénier, M., 2008. Influence of matrix composition on the bioaccessibility of Copper, Zinc, and Nickel in urban residential dust and soil. Hum. Ecol. Risk Assess. 14, 351-371.

Roussel, H., Waterlot, C., Pelfrene, A., Pruvot, C., Mazzuca, M., Douay, F., 2010. Cd, Pb and $\mathrm{Zn}$ oral bioaccessibility of urban soils contaminated in the past by atmospheric emissions from two lead and zinc smelters. Arch. Environ. Contam. Toxicol. 58, 945-954

Ruby, M.V., Davis, A., Link, T.E., Schoof, R., Chaney, R.L., Freeman, G.B., Bergstrom, P., 1993. Development of an in vitro screening test to evaluate the in vivo bioaccessibility of ingested mine-waste lead. Environ. Sci. Technol. 27, 28702877.

Ruby, M.V., Davis, A., Schoof, R., Eberle, S., Sellstone, C.M., 1996. Estimation of lead and arsenic bioavailability using a physiologically based extraction test. Environ. Sci. Technol. 30, 422-430.

Ruby, M., Schoof, R., Brattin, W., Goldade, M., Post, G., Harnois, M., Mosby, D.E., Casteel, S., Berti, W., Carpenter, M., Edwards, D., Cragin, D., Chappell, W., 1999. Advances in evaluating the oral bioavailability of inorganics in soil for use in human health risk assessment. Environ. Sci. Technol. 33, 3697-3705.

Sadic, M., 1997. Arsenic chemistry in soils: an overview of thermodynamic predictions and field observations. Water Air Soil Pollut. 93, 117-136.

Tseng, W.P., 1977. Effects and dose-response relationships of skin cancer and blackfoot disease with arsenic. Environ. Health Perspect. 19, 109-119.

Tseng, W.P., Chu, H.M., How, S.W., Fong, J.M., Lin, C.S., Yeh, S., 1968. Prevalence of skin cancer in an endemic area of chronic arsenicism in Taiwan. J. Natl. Cancer Inst. $40,453-463$.

USEPA, 2010. Integrated Risk Information System IRIS. <http:/www.epa.gov/ncea/ iris/subst/0278.htm>

Yang, J., Barnett, M.O., Jardine, P.M., Basta, N.T., Casteel, S.W., 2002. Adsorption, sequestration, and bioaccessibility of $\mathrm{As}(\mathrm{V})$ in soils. Environ. Sci. Technol. 36, 4562-4569. 